that makes their practices acceptable.

The Warnock committee should therefore pass part of the buck with which it has been stuck back to the academic embryologists. What is to be made of the applications of the new techniques? The obvious difficulty for Warnock is that in Britain medicine differs from that in most other industrialized states in that those who practise it do not have to be registered with the state. Homoeopathy flourishes, osteopathy is in good shape and there is no law to prevent one person telling another that influenza may be cured by an infusion of herbs picked from some hedgerow at full moon. To be sure, people are regularly sent to gaol for passing themselves off as registered medical practitioners, or for extorting money from those from whose desperation in illness they unfairly win financial gain, but there is nothing to prevent private people from operating sperm banks, AID clinics or the like except the general injunction against advertising, the chance that they would be less likely than qualified physicians to recruit patients and the financial risks of being sued for damages in an unsympathetic court if something went wrong.

Warnock cannot follow the advice offered by the Royal College of Obstetricians and Gynaecologists that all establishments at which in vitro fertilization is carried out should be registered under some new legislation without tilting at a long-established principle underlying British medicine. But how, then, could it consistently draw a line between in vitro fertilization or embryo transfer on the one hand and the now long-established practice of AID? Here again, the best course will be to ask that all embryonic manipulations should be discussed with some ethical committee having a statutory existence, that appropriate data should be recorded confidentially but in such a way that they could afterwards be recovered and that there should be some means of letting the world know, after the event, what has been done. The simple way of doing that is to set up a formal group along the lines of the genetic manipulation committee to exert a general supervisory influence on local ethical committees, to consider difficult questions as they arise and to keep the general public informed of what is going on. There could be no assurance, of course, that the need for such a committee would melt away. In genetic manipulation, the need for the committee disappeared as evidence accumulated that the dangers of research had been pitched too high. In embryology, ordinary people's beliefs can be changed only by public argument.

\section{Which pipers to pay?}

\section{The United States should find a better way of paying the true cost of research.}

THE time at which the grant-making organizations in the United States should have come to a decision about indirect costs has long since passed. The issue is the degree to which research grants by agencies such as the National Institutes of Health (NIH) should be inflated by an amount that will compensate the recipient university or institution for the time and trouble involved in spending the money. That universities incur extra costs when their academics succeed in the increasingly cut-throat competition that passes in Washington for a market in bright ideas is not disputed, in which sense the agencies' admission that indirect costs must somehow be met is but an acknowledgement that academic research needs two kinds of support, the direct cost of research projects and some element of overhead cost. So why (see page 742) is there now in prospect another round of argument about the percentages that NIH will henceforth pay, on top of the nominal value of research grants, to recipient institutions? Two obstacles stand out - the diversity of recipients (state but also private universities) and of donors (NIH, the Pentagon and so on). Most European governments meet the need differently, by subsidizing possible recipients with too little discrimination. The ideal probably lies in the proposal canvassed but then defeated in Congress in the 1960s that there should be general subsidies to research institutions with a proven record of success. Why not dust it off?

\section{Peace makes problems}

Britain's domestic argument about nuclear weapons is getting nasty, with both sides in the wrong.

WITH a British general election perhaps only a few weeks and at the most a few months away, it is understandable but also unforgivable that the Secretary of State for Defence, Mr Michael Heseltine, should have attacked the British Campaign for Nuclear Disarmament (CND) on the grounds that many of its leading members manifest "the calculating professionalism of full-time socialists and communists". For the organization has its roots in the heady days of the late $1950 \mathrm{~s}$, when the late Mr Hugh Gaitskell persuaded the then-putative Labour government (eventually elected in 1964) to stick by the collaborative defence of Western Europe by means of nuclear weapons if necessary. That argument was so fiercely but openly conducted, and so educative even for those not directly involved, that the stripling CND was regarded not as a subversive organisation but as a kind of necessary, but exceedingly polite, consequence of a resounding defeat. Its fortunes quickly faded.

Since then, the campaign has made its way in the world by marching from one defence establishment to another, usually in the rain at Easter. Its membership has been revived since the decision at the end of 1979 by the Council of the North Atlantic Treaty Organization that it would be prudent from the end of 1983 to base intermediate-range nuclear weapons in Western Europe if an agreement with the Warsaw Pact states had not by then been reached. The campaign is now loudly protesting that Mr Heseltine's charge of "left-wing domination" is a "smear", which is in the strict sense true. In states such as those of Western Europe, in which there is no law against communist, let alone socialist, opinions, to complain that left-wingers dominate elected committees of voluntary organizations is strictly speaking beside the point. The same complaint might just as well be made against several trade unions in Western Europe.

The recent general election in West Germany is a vivid pointer to the issues with which organizations such as the campaign are concerned. From the particular to the general, they are as follows: - Given accepted assumptions about strategic policy, do the practical arrangements foreseen make sense? In Britain, many people (including at least one former Foreign Secretary, Dr David Owen) answer in the negative to the proposition that Trident should replace Polaris submarines, for example.

- Whatever the arrangements for coordinated defence, does not a national government's possession of or hospitality for nuclear weapons diminish the chance of immunity from attack? (The simple answer is yes, the more complicated is the question "What if everybody concluded that?")

- Are not nuclear weapons such abominations that they should be foresworn? (Of course: but arms control hangs fire.)

Western European opinion against nuclear weapons is untidily organized around one or more of these questions. Governments would be better advised to find better ways of answering them than to broaden their attack in constitutionally uncomfortable ways.

The peace, or protest, movements also need to be more circumspect. On 19 April, an offshoot of the campaign called the "CND Sizewell Working Group"' published a pamphlet called The Plutonium Connection, intended as a basis of its evidence against a proposal to build a nuclear power station in Suffolk. Mercifully, on the basis of a decision by the Sizewell inspector last week, there is now a good chance that the case will be inadmissible, but how can an organization supposedly dedicated to the admittedly urgent question of strategic arms spare so much effort to argue against a nuclear reactor that cannot function within the decade? And how can an organization with purportedly clear motives join in, as CND will be doing this week in London, a "Green Rally" whose objective seems to be to form a party of Greens on West German lines? Single-cause pressure groups merely invite smears when they, like their attackers, stray from the central issues. 